\title{
Detection efficiency of the VLF World-Wide Lightning Location Network (WWLLN): initial case study
}

\author{
C. J. Rodger ${ }^{1}$, S. Werner ${ }^{1}$, J. B. Brundell ${ }^{2}$, E. H. Lay ${ }^{3}$, N. R. Thomson ${ }^{1}$, R. H. Holzworth ${ }^{3}$, and R. L. Dowden ${ }^{2}$ \\ ${ }^{1}$ Department of Physics, University of Otago, Dunedin, New Zealand \\ ${ }^{2}$ LFEM Research Ltd., 161 Pine Hill Road, Dunedin, New Zealand \\ ${ }^{3}$ Dept. Earth and Space Sciences, University of Washington, USA
}

Received: 20 July 2006 - Revised: 26 October 2006 - Accepted: 27 October 2006 - Published: 21 December 2006

\begin{abstract}
An experimental Very Low Frequency (VLF) World-Wide Lightning Location Network (WWLLN) has been developed through collaborations with research institutions across the world, providing global real-time locations of lightning discharges. As of April 2006, the network included 25 stations providing coverage for much of the Earth. In this paper we examine the detection efficiency of the WWLLN by comparing the locations from this network with lightning location data purchased from a commercial lightning location network operating in New Zealand. Our analysis confirms that WWLLN favours high peak current return stroke lightning discharges, and that discharges with larger currents are observed by more stations across the global network. We then construct a first principles detection efficiency model to describe the WWLLN, combining calibration information for each station with theoretical modelling to describe the expected amplitudes of the VLF sferics observed by the network. This detection efficiency model allows the prediction of the global variation in WWLLN lightning detection, and an estimate of the minimum CG return stroke peak current required to trigger the network. There are strong spatial variations across the globe, primarily due to station density and sensitivity.
\end{abstract}

The WWLLN is currently best suited to study the occurrence and impacts of high peak-current lightning. For example, in 2005 about $12 \%$ of the global elve-producing lightning will have been located by the network. Since the lightning-EMP which produce elves has a high mean rate (210 per minute) it has the potential to significantly influence the ionosphere on regional scales.

Keywords. Meteorology and atmospheric dynamics (Atmospheric electricity; Lightning; Instruments and techniques)

Correspondence to: C. J. Rodger

crodger@physics.otago.ac.nz

\section{Introduction}

Lightning discharges are powerful impulsive sources of electromagnetic energy over a wide bandwidth (Magono, 1980), with the bulk of the energy radiated in the frequency bands $<30 \mathrm{kHz}$ (Pierce, 1977). Passive lightning location methods rely upon the energy released by the lightning discharge, acoustically (thunder), optically (lightning), and in the radio frequency spectrum (Uman, 1987). Today, commercial lightning location networks are in operation in many regions of the world, using multiple stations to locate the source of lightning electromagnetic radiation pulses (Rakov and Uman, 2003). The economic advantages that many groups obtain from accurate and virtually instantaneous lightning location data, results in these data being in high demand from many industries such as electricity generators and distributors, aviation, forestry, sporting groups, insurance companies and weather forecasters (Cummins et al., 1998a). In addition to these groups, there is also strong scientific interest in the application of lightning data to a wide range of research topics including lightning and related thunderstorm processes (Lyons et al., 1998), severe weather warning (Knupp et al., 2003), high altitude discharges (Rodger, 1999), global warming (Williams, 1992; Schlegel et al., 2001), regional meteorological processes (Hamid et al., 2001), production of important trace chemicals (Jourdain and Hauglustaine, 2001), determination of ionospheric parameters (Cummer et al., 1998), and magnetospheric wave-particle interactions (Rodger et al., 2003).

Multi-station lightning location systems generally consist of a number of spatially separated receiver stations positioned on the surface of the Earth (although some single station techniques also exist, e.g., Huang et al., 1999). In multistation lightning location systems the information from each station is, on its own, insufficient to enable the location of the discharge to be determined. However, when the information from some or all of these stations is combined together at a

Published by Copernicus GmbH on behalf of the European Geosciences Union. 


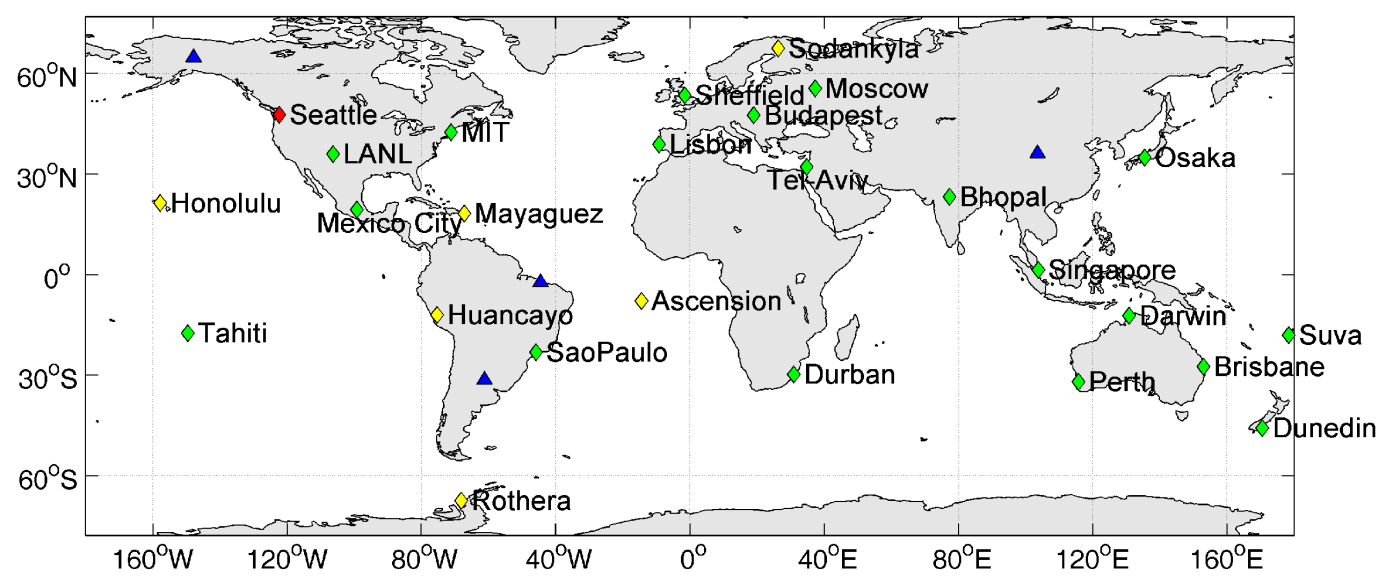

Fig. 1. Locations and hosts of the 25 VLF receiving stations operating in the VLF World-Wide Lightning Location Network as of April 2006. The 20 stations included in the detection efficiency analysis are marked as green diamonds, while new stations are yellow diamonds (however, note the comment on Bhopal in the Table 1 caption). The location of the central processing computer plus receiver is shown as a red diamond, while the planned locations of future WWLLN sites are shown as blue triangles.

central site, the location of the discharge can be determined. In general single-station techniques are cheaper to operate but less accurate, while multi-station networks tend to offer higher location accuracy and detection efficiency. An example is the United States National Lightning Detection Network (NLDN), which in 1996 used 106 sensors located over the continental United States to achieve a typical accuracy of $0.5 \mathrm{~km}$ (Cummins et al., 1998b). Many commercial lightning detection networks require such high location accuracies to allow electrical power transmission companies to quickly locate lightning-produced line faults or to assist insurance inspectors in checking claims. Such networks rely upon the first few microseconds of the lightning pulse received in the Medium Frequency (MF) band (0.3-3 MHz), thus avoiding the sky wave (that which reflects from the ionosphere), by processing only the ground wave (which has high attenuation at the high frequencies used). Thus NLDN requires $>100$ ground stations to cover the contiguous US $\left(\sim 10^{7} \mathrm{~km}^{2}\right)$, corresponding to a ground station density of $\sim 10 \mathrm{Mm}^{-2}$. Such a high density of stations makes these systems poorly suited for coverage of areas with low population density, or economic development, or across the oceans.

Low-Frequency Electromagnetic Research Ltd. has created an experimental Very Low Frequency (VLF) WorldWide Lightning Location Network (WWLLN) through collaborations with research institutions across the globe (Fig. 1 shows the April 2006 network configuration). The network exploits the considerable electromagnetic power radiated by lightning as "sferics" present in the VLF band $(3-30 \mathrm{kHz})$. Very long range remote sensing is possible; these VLF signals can be received thousands of kilometres from the source (Crombie, 1964), as the electromagnetic energy propagates with low attenuation inside the waveguide formed by the conducting Earth and the lower boundary of the ionosphere, termed the Earth-Ionosphere Waveguide (EIWG). The vertical electric field from strong lightning normally dominates over power line noise in the receiver bandwidth $(6-22 \mathrm{kHz})$, such that the WWLLN receiving stations have relative freedom from the restriction of noise-free receiver locations required for other long-range lightning location techniques (e.g., Fullekrug and Constable, 2000). The use of differing sferic frequency ranges (e.g., VLF versus MF) in multistation lightning location networks has been discussed by Cummins and Murphy (2000) and Dowden et al. (2002). The ultimate aim of the WWLLN is to provide real-time locations of cloud-to-ground lightning discharges occurring anywhere on the globe, with $>50 \%$ flash detection efficiency and mean location accuracy of $<10 \mathrm{~km}$.

The location accuracy and regional detection efficiency of the WWLLN network has been examined by contrasting its observations with those from MF/HF lightning detection networks in Australia, Brazil, and America (e.g., Lay et al., 2004; Rodger et al., 2004, 2005; Jacobson et al., 2006). These studies indicated that WWLLN does indeed detect strong lightning discharges in various parts of the Earth, and produced estimates for the global location accuracy. A very recent study showed that WWLLN detects lightning-producing storms with high efficiency inside a 3-h time period, showing that WWLLN can be useful for locating deep convection for weather forecasting on the rather common meteorological 3-h update cycle (Jacobson et al., 2006). From these studies it is clear that the detection efficiency is low, with a few percent of global lightning activity detected (e.g., Rodger et al., 2005). For many scientific applications, the benefits of a global overview in real time can outweigh the very low total lightning detection. Observations of red sprites undertaken from the space shuttle Columbia during the ill-fated STS107 mission used WWLLN activity maps 
Table 1. Locations and hosts of the 25 VLF receiving stations currently operating in the VLF World-Wide Lightning Location Network. Note that the Bhopal station, which is included in the detection efficiency analysis presented in this study, was retired from the WWLLN in late December 2005 due to technical problems, and thus 26 stations are included in the table. The solid line indicates the 20 WWLLN stations which were included in the calibration campaign period.

\begin{tabular}{lrrl}
\hline Location & Latitude $(\mathrm{N})$ & Longitude $(\mathrm{E})$ & Host \\
\hline Dunedin & -45.8639 & 170.514 & University of Otago \\
Darwin & -12.3718 & 130.868 & Northern Territory University \\
Perth & -32.0663 & 115.836 & Murdoch University \\
Osaka & 34.8232 & 135.523 & Osaka University \\
Singapore & 1.2971 & 103.779 & National University of Singapore \\
Brisbane & -27.5534 & 153.052 & Griffith University \\
Suva & -18.1489 & 178.4459 & University of the South Pacific \\
LANL & 35.8721 & -106.328 & Los Alamos National Laboratory \\
Budapest & 47.4748 & 19.062 & Eötvös University \\
Seattle & 47.654 & -122.309 & University of Washington \\
MIT & 42.3604 & -71.0894 & Massachusetts Institute of Technology \\
Durban & -29.8711 & 30.9764 & University of KwaZulu-Natal \\
Bhopal & 23.2146 & 77.4363 & Barkatullah University \\
Sao Paulo & -23.2075 & -45.8595 & Instituto Nacional de Pesquisas Espaciais \\
Tahiti & -17.5767 & -149.609 & Universite de la Polynesie Francais \\
Mexico City & 19.3261 & -99.1764 & Universidad Nacional Autonoma de Mexico \\
Tel Aviv & 32.1130 & 34.8062 & Tel Aviv University \\
Lisbon & 38.7758 & -9.1257 & Portugal Meteorological Institute \\
Sheffield & 53.3811 & -1.4779 & University of Sheffield \\
Moscow & 55.4765 & 37.3143 & Institute of Terrestrial Magnetism, \\
& & & Ionosphere and Radiowave Propagation \\
\hline Huancayo & -12.053 & -75.2863 & Instituto Geofisico del Peru \\
Mayagüez & 18.2096 & -67.1395 & University of Puerto Rico \\
Honolulu & 21.2991 & -157.816 & University of Hawaii at Manoa \\
Sodankyla & 67.4209 & 26.39 & University of Oulu \\
Rothera & -67.5691 & -68.1245 & British Antarctic Survey \\
Ascension & -7.95005 & -14.3781 & British Antarctic Survey \\
\hline & & & \\
& & & \\
\hline
\end{tabular}

available from the internet to orientate the shuttle (Yair et al., 2004), allowing some predication of where active thunderstorms containing the large lightning events associated with transient luminous events (e.g., sprites) would be located. Other recent scientific studies have made use of WWLLN observations to provide continuous lightning observations in parts of the world where coverage is provided only by brief and rare satellite overpasses (e.g., Yair et al., 2005; Collier et al., 2006).
In this paper we examine the detection efficiency of the WWLLN by comparing the lightning locations reported by this network with lightning location data purchased from a New Zealand commercial lightning location network. We go on to construct a first principles detection efficiency model to describe the WWLLN, combining calibration information for each station with theoretical modelling to describe the expected amplitudes of the VLF sferics observed by the network, and hence determine the detection efficiency of the network. 


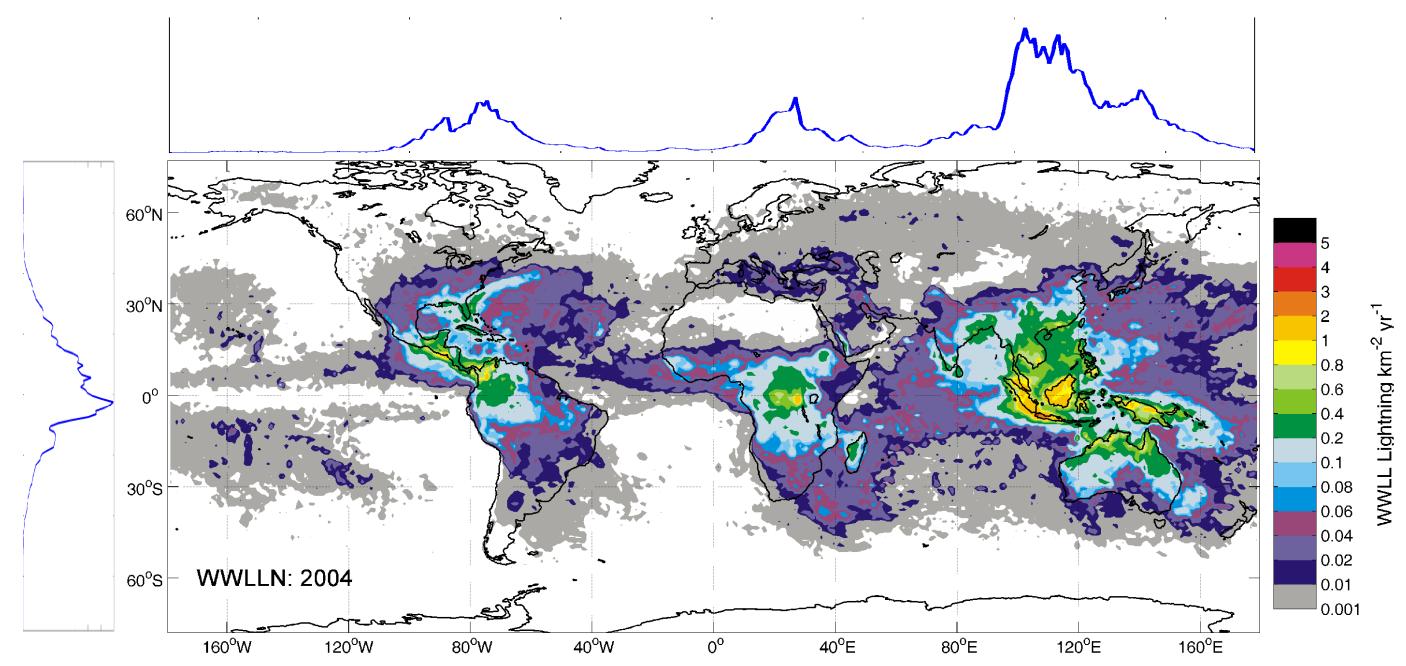

Fig. 2. Summary of 2004 WWLLN lightning activity. The density map shows the annualized geographical distribution of total lightning activity in units of flashes $\mathrm{km}^{-2} \mathrm{yr}^{-1}$. The upper and left hand panels show how the activity varies with longitude and latitude, respectively.

\section{WWLLN description}

The basic operation of the WWLLN receiving stations, the location finding process, and time of group arrival (TOGA) calculation are described in Dowden et al. (2002), while network operation issues associated with stroke selection and data management have been discussed in Rodger et al. (2004). The nature of the "standard" VLF WWLLN receiving stations and sferic selection process was outlined in Rodger et al. (2005). As of April 2006 the WWLLN consisted of 25 operational receiving stations shown as diamonds in Fig. 1 and listed in Table 1. Each station consists of an electric field "whip" antenna, processing computer, and an internet connection to send TOGA values back to the central processor. The solid line in Table 1 indicated the 20 WWLLN stations which were included in the study on WWLLN detection efficiencies, described below. Note that the Bhopal station was retired in December 2005 due to technical problems, as was the station in Tainan (Taiwan) listed in earlier WWLLN publications (e.g., Rodger et al., 2005) in early 2005, leading to the total of 26 stations listed in Table 1 .

The WWLLN central processing computers (CPCs) are located in Seattle (USA). The Dunedin (New Zealand) central processor was shut-down in August 2005, but is planned to return in mid-2006. Further receiver stations are planned for South America and Central Asia, as shown by the blue triangles in Fig. 1. However, as seen in the figure, the WWLLN stations are far from being uniformly spaced, despite the rapid growth over the last 4 years.

Figure 2 shows the global lightning activity reported by the WWLLN for 2004. This plot includes 19.7 million "high quality" WWLLN determined lightning locations, defined by the WWLLN operators as events with residuals less than $30 \mu$ s and where $\geq 5$ WWLLN stations participated in pro- viding the locations. The central density map in Fig. 2 shows the annualized geographical distribution of total lightning activity in units of flashes $\mathrm{km}^{-2} \mathrm{yr}^{-1}$, to be contrasted with the average geographic global flash rate variation (Christian et al., Fig. 4, 2003) observed by the Optical Transient Detector (OTD) satellite over 5 years. Clearly, some of the expected features for "typical" lightning distributions, as reported by the OTD mission, are present in the 2004 WWLLN lightning activity map, particularly in the "Maritime Continent" (South-East Asia, northern Australia and the Indonesian archipelago). Regions of greater lightning density in the WWLLN locations generally correspond to land masses, as expected. Nonetheless, the WWLLN lightning activity currently reflects the relative station densities (Fig. 1), favouring the Maritime Continent, the weaker of the three thunderstorm "chimney" regions (Orville and Henderson, 1986), over the other two regions (America and Africa). However, the strongest lightning producing region, Africa (e.g., Christian et al., 2003), is currently fairly well represented in the data when one considers the low number of stations in this region.

The upper and left hand panels of Fig. 2 show how the 2004 WWLLN lightning activity varies with longitude and latitude, respectively. This figure should be contrasted with the classic Carnegie curve for regional thunderstorm occurrence (Whipple and Scrase, 1936), which shows the dominance of the three tropical chimney regions. While the diurnal global thunderstorm occurrence expressed through the Carnegie curve suggests that lightning activity is strongest in Africa/Europe, followed by the Americas and finally the Maritime Continent, the 2004 WWLLN data had a much stronger Maritime Continent contribution reflecting the local station density. 


\section{Comparison with commercial lightning location data}

In previous studies the location accuracy and detection efficiency of the WWLLN was examined by making a comparison with commercial MF lightning location systems. Relatively small time periods were used to contrast lightning observations from the differing systems in Australia (Rodger et al., 2004; 2005) and Brazil (Lay et al., 2004). Here we follow the approach outlined for Australia, but using a much longer lightning data set collected in and around New Zealand.

\subsection{NZLDN lightning location data}

The New Zealand Lightning Detection Network (NZLDN) is operated by the New Zealand MetService. The NZLDN is comprised of ten IMPACT ESP2 sensors, deployed to provide optimal detection efficiencies and location accuracies for Cloud to Ground (CG) return strokes (and not flashes) with peak currents $\geq 5 \mathrm{kA}$. Industry standard software for modelling network performance suggests that the NZLDN will achieve better than 1-km location accuracy and at least a 90\% stroke detection efficiency over almost the entire country (personal communication, P. Fisher, MetService, 2004). It should be noted that peak currents of $<10 \mathrm{kA}$ were not removed from the data set, as is sometimes the practice using National Lightning Detection Network (NLDN) data. The NZLDN estimates the peak return stroke currents in the same way as other commercial lightning detection networks, such as the United States NLDN (Cummins et al., 1998b). Figure 3 shows the annualized geographical distribution of NZLDN CG stroke density $\left(0.1^{\circ}\right.$ resolution) from the beginning of network operations 22 August 2000 through to 15 August 2004. The strong cutoffs in lightning density seen well off the coastlines in the far north and the south east of the country are due to decreasing detection efficiencies. While lightning densities in New Zealand are relatively low compared with much of the world (e.g., Christian et al., 2003), we note the strong orographic effect of the Southern Alps mountain chain on the West Coast of the South Island, where the peak lightning activity lies. Electrical activity in convective systems moving eastward off the Tasman Sea (located in the west of the figure) appears initially enhanced by the rising terrain of the Southern Alps, but is then largely suppressed once travelling to the other side of the mountain range.

\subsection{Contrasting the NZLDN and WWLLN}

Both the NZLDN and WWLLN locations were restricted to a spatial window around New Zealand given by the following limits: longitudes from $165^{\circ} \mathrm{E}-180^{\circ} \mathrm{E}$, latitudes from $34^{\circ} \mathrm{S}-49^{\circ} \mathrm{S}$. This rectangle was designed to include all the NZLDN high detection efficiency (DE) area. Lightning events reported by both systems were included from 1 October 2003, when the TOGA algorithm was implemented in the WWLLN, through to 31 December 2004.

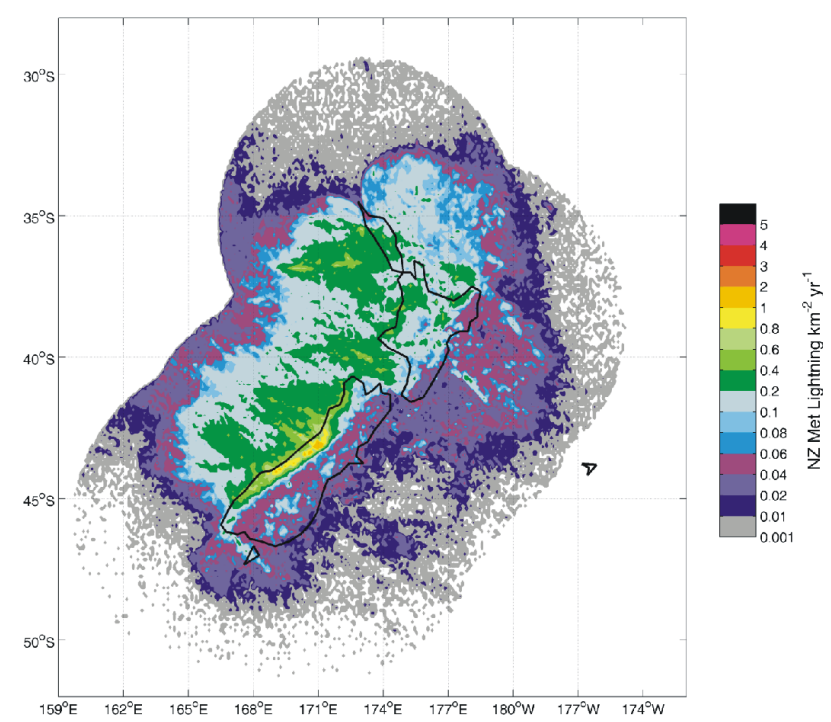

Fig. 3. The annualized geographical distribution of New Zealand CG lightning density determined from nearly 4 years of NZLDN data in units of strokes $\mathrm{km}^{-2} \mathrm{yr}^{-1}$.

Inside the spatial window and over this time period there were 204,411 NZLDN CG strokes and 19,810 NZLDN intracloud (IC) lightning strokes (sometimes termed "cloud discharges"). In general, it is understood that there are $\sim 3.5$ times more IC lightning flashes than CG flashes (Mackerras et al., 1998), and thus one might expect there to be considerably more IC events present in Fig. 2. However, the NZLDN receiver technology is strongly focused towards the detection and accurate location of the stronger CG discharges, and has a fairly low IC detection efficiency (as do other, similar systems, e.g., NLDN). CG and IC identification is through waveform acceptance criteria (Rakov and Uman, 2003).

Unlike in our earlier studies, the NZLDN lightning locations were available with nano-second time resolution (c.f. the Australian Kattron data of Rodger et al. $(2004,2005)$ had $1 \mathrm{~ms}$ timing at best), while the WWLLN data has $1 \mu \mathrm{s}$ resolution which is sufficient to meet its DE needs. In order to make comparisons between the location estimates for CG lightning discharges by the NZLDN and WWLLN network data, WWLLN events were selected which occurred within $\pm 0.5 \mathrm{~ms}$ of a lightning event detected by NZLDN inside the selected region. No restriction was placed on the spatial separation. Note that the time difference and spatial separation limits are different from those employed in earlier studies (Rodger et al., 2004, 2005; Lay et al., 2004). However due to the to the very high time resolution of the NZLDN and WWLLN data, plus the low New Zealand lightning rates, the timing alone should be sufficient to determine all matching events in the two data sets. Under these restrictions a total of 5923 WWLLN lightning discharges were found to match NZLDN CGs, i.e., an average DE of 3\% for this 15 month 


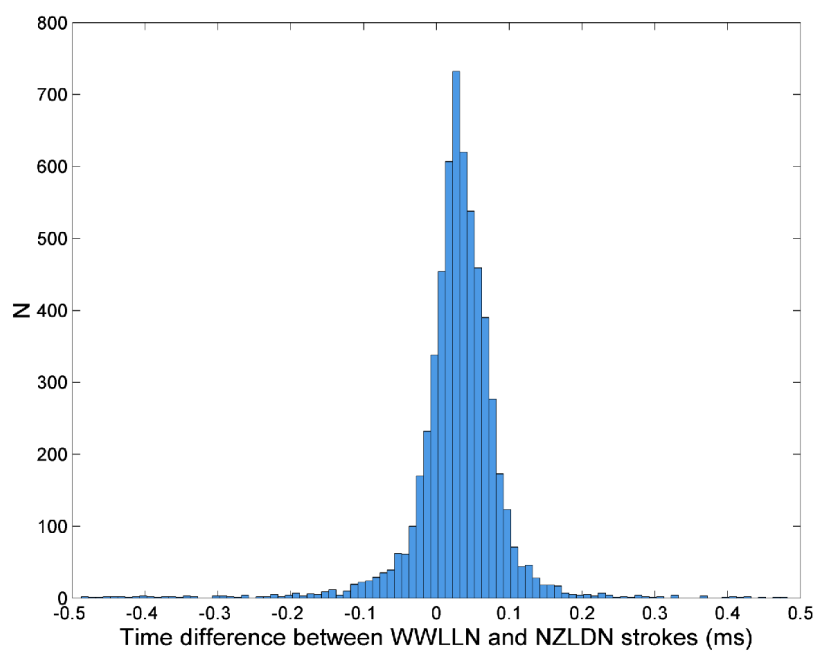

Fig. 4. Time differences (WWLLN-NZLDN) between the 5923 matching CG events detected by the WWLLN and NZLDN.

period. Note that this DE is influenced by the lack of a lower peak current threshold in NZLDN data. There are only 153154 NZLDN CG strokes and the same number of IC strokes if a $10 \mathrm{kA}$ lower current threshold is taken, leading to an average DE of $3.8 \%$ for this 15 month period.

The long-term average DE of 3\% is vastly lower than the $\sim 25 \%$ DE reported for a single day's lightning observations in South-Eastern Australia (Rodger et al., 2005). This lower DE can be partly explained by station locations and propagation, as outlined in Sect. 6.3 below. The time differences between the NZLDN and WWLLN events are shown in Fig. 4 where the mean time difference is $32 \mu \mathrm{s}$. Clearly there is a slight offset, such that the WWLLN tends to report CGs $\sim 0.03 \mathrm{~ms}$ after the NZLDN reports the same event. Note that there are almost no matching lightning events with time differences greater than $\pm 0.15 \mathrm{~ms}$, giving us good confidence we are correctly identifying coincident lightning observations.

Previous WWLLN studies have argued that the VLF network also detects ICs. There were 7536 WWLLN reported discharges which did not match to NZLDN CGs. However, 190 of these discharges do occur within $\pm 0.5 \mathrm{~ms}$ of NZLDN reported ICs, suggesting that $\sim 1 \%$ of the NZLDN reported IC's were also reported by the WWLLN. However, in addition there are 7346 WWLLN locations in this region which do not correspond to NZLDN reported CG or IC strokes. On the basis of analysis of the upgraded Los Alamos Sferic Array (Smith, et al., 2002), the vast majority of these "missing" WWLLN locations are likely to be IC discharges which NZLDN has not reported (Jacobson et al., 2006). The latter study reports that the WWLLN false detection rate is low, assuming that the Los Alamos Sferic Array sees all CG and non-CG events that occur. If we assume that the NZLDN $\mathrm{DE}$ is $\sim 95 \%$, such that there were 249134 total lightning

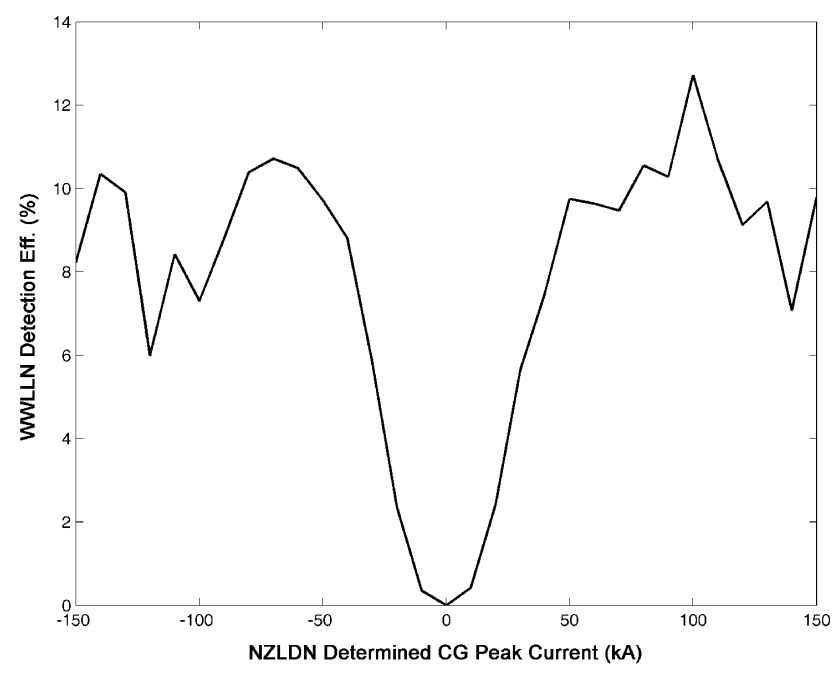

Fig. 5. Variation in the WWLLN CG stroke detection efficiency with NZLDN-determined return stroke peak current.

strokes (CGs + ICs), the 13459 WWLLN-detected strokes corresponds to a total lightning DE of $\sim 5.4 \%$ in the NZ region. We will, however, focus on the CG detection efficiency so as to develop a DE model based on the well-known distribution of CG return stroke peak currents.

\subsection{Dependence upon peak current}

The main goal of our comparison was to examine the detection efficiency of the WWLLN relative to the NZLDN. Several earlier studies have noted that the WWLLN tends to detect the strongest lightning (e.g., Lay et al., 2004). The mean absolute peak current for all NZLDN reported CG lightning is $23.4 \mathrm{kA}$, while the median absolute peak current is $15.5 \mathrm{kA}$. In contrast, the mean absolute peak current for the CG strokes which are observed by both NZLDN and WWLLN is $46.2 \mathrm{kA}$, while the median is $37.5 \mathrm{kA}$. Similar results are found for cloud flashes, with the mean absolute peak currents for all NZLDN cloud discharges being only $16.3 \mathrm{kA}$ (c.f. $41.2 \mathrm{kA}$ for strokes detected by both systems) and the median being $11.8 \mathrm{kA}$ (c.f. $37.2 \mathrm{kA}$ for strokes detected by both systems). Clearly, the WWLLN is strongly biased towards stronger lightning with higher peak currents. This is emphasised by Fig. 5, showing the variation in the WWLLN CG stroke detection efficiency against NZLDN-determined return stroke peak current using $10 \mathrm{kA}$ bins. A similar approach was taken in the comparison of lightning observations between the Los Alamos Sferic Array and WWLLN (Jacobson et al., Fig. 5, 2006), also producing a "bathtub" curve. Here we assume for the sake of argument that the NZLDN has a $100 \%$ DE. While the average WWLLN DE is only $\sim 3 \%$ for all NZLDN-reported CG discharges it is considerably higher for the stronger peak currents, being $\sim 9-10 \%$ for return stroke peak currents $>50 \mathrm{kA}$. Beyond $\sim 80 \mathrm{kA}$ the 


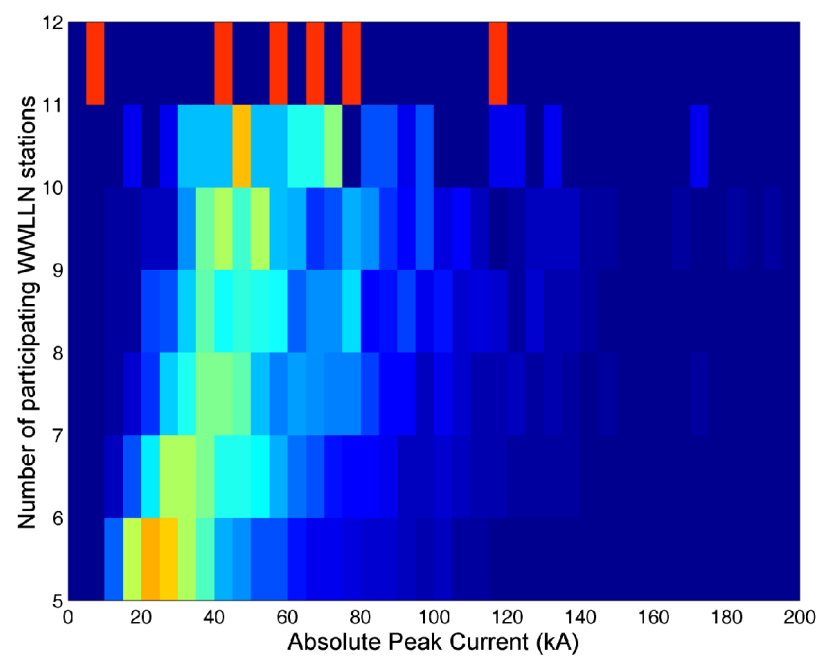

Fig. 6. The distribution of NZLDN-determined CG return stroke peak currents against the number of WWLLN stations participating in the location finding.

population is small leading to poor statistics, although the $\sim 10 \%$ relationship seems to roughly hold. We interpret Fig. 5 as showing that lightning with small return stroke peak currents produces VLF sferics which are too weak to trigger at the required 5 (or more) WWLLN stations, and hence be reported by the network. However, once the discharge is sufficiently strong, in this case about $>50 \mathrm{kA}$, all such lightning will trigger the network, and the DE is determined by limitations in the algorithm by which each timing measurement from the stations are combined to select a common stroke and find the location.

A further example of the influence of the return stroke peak current upon WWLLN detection can be seen in Fig. 6, where the distribution of NZLDN-determined CG return stroke peak currents is plotted against the number of WWLLN stations which participated in the location finding. The colour scale in this figure is indicative to the number of stations participating, with "hotter" colours indicating more stations. There is a clear shift to higher NZLDNdetermined return stroke peak currents for the larger numbers of WWLLN stations participating in the location finding, at least up to $\sim 10$ stations, after which the number of observations becomes too low to produce an observable signature. The pattern in Fig. 6 is consistent with the interpretation outlined above, where stronger return stroke peak currents will produce high amplitude sferics which will trigger more WWLLN stations.

\section{Detection range of WWLLN stations}

Figure 6 indicates that under some conditions WWLLN stations can detect lightning at very large distances, as expected

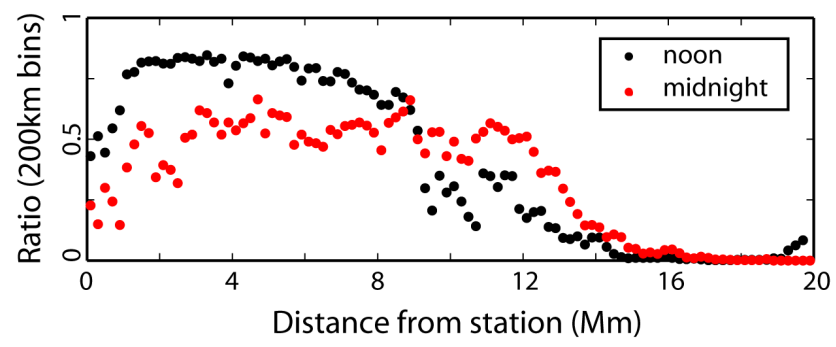

Fig. 7. Ratio of the number of events detected by the Darwin station to the number of events detected at the same range from Darwin by the network as a whole. The black dots show this ratio for $\pm 2 \mathrm{~h}$ around local noon, while the red dots are for $\pm 2 \mathrm{~h}$ around local midnight.

from fundamental VLF propagation (Crombie, 1964). By using WWLLN observational data we can characterise the typical WWLLN station observing range, i.e., at what distance can a particular station detect a lightning stroke. We use a sample of WWLLN data from 1-30 April 2005 to determine the detection range of each station. To calculate the detection range, we find which events of the entire WWLLN data set each station participated in detecting. For this example, we will discuss and calculate the detection range of the Darwin WWLLN station. We calculate the distance between the Darwin station location and each lightning event that was detected at the Darwin WWLLN station. We then determine the number of events Darwin detected versus distance from the station, in $200-\mathrm{km}$ bins, as well as the number of events the WWLLN as a whole detected versus distance from Darwin. Because of the spherical geometry of the Earth, the bins increase in area until $10 \mathrm{Mm}$ (a quarter of the Earth's circumference) and then decrease in area for the larger distances. Thus, the bins that contain data from $10 \mathrm{Mm}$ have better statistics than those at either $1 \mathrm{Mm}$ or $20 \mathrm{Mm}$. Figure 7 shows a histogram of the ratio of the events the Darwin WWLLN station "saw" over the total number of events the WWLLN network detected versus the distance of the lightning stroke from the Darwin station. A ratio of one would indicate that the Darwin station participated in the detection of all the lightning that the WWLLN reported in that 200-km-width bin. The black dots show the ratio for events that occurred $\pm 2 \mathrm{~h}$ around local noon, and the red dots show the ratio for events that occurred $\pm 2 \mathrm{~h}$ around local midnight. While lightning located very distant to the Darwin WWLLN station may have propagated under a mixture of both day and night ionospheres when considering the case of local noon at Darwin, this situation will be dominated by the daytime ionospheric propagation conditions around the WWLLN station. The plots show that Darwin has a larger detection range around local midnight than around local noon, as is expected because of ionization density changes between day and night in the Earth-Ionosphere Waveguide, leading to lower attenuation for propagation under the nighttime ionosphere than 


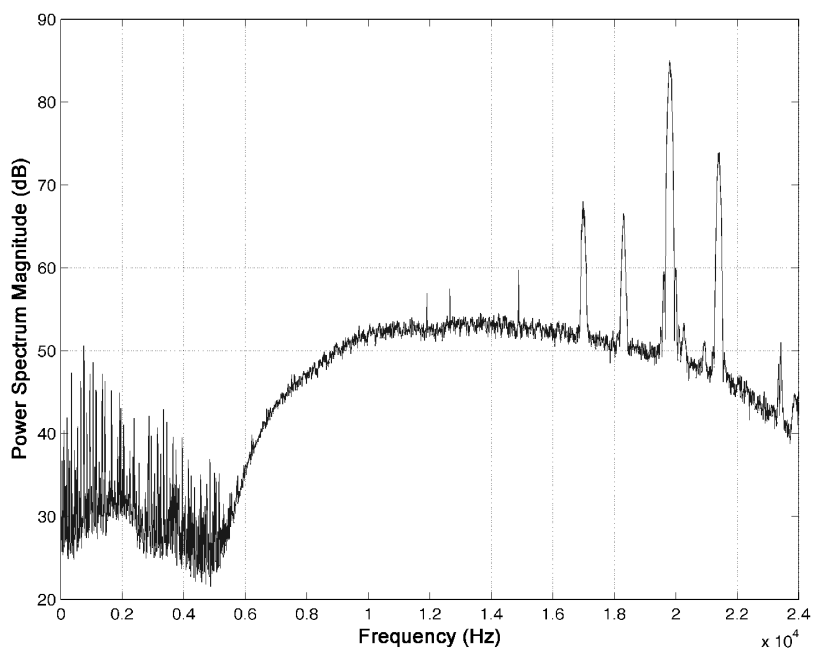

Fig. 8. Power spectral density of the VLF waveform observed at the WWLLN station in Dunedin, New Zealand, over $15 \mathrm{~s}$ starting at 02:00 UT on 3 December 2004.

for propagation under the daytime ionosphere (Watt, 1967). This effect is typical of all the WWLLN stations. The plots also show that during the day, Darwin detects the majority of lightning within $\sim 8 \mathrm{Mm}$, and then the detection ability drops to zero at around $14 \mathrm{Mm}$. There is an exception for strokes that occur within $\sim 0.5 \mathrm{Mm}$ of Darwin. Strokes that occur very near Darwin will have low propagation-produced dispersion and may not have an expected dispersed waveform at the station. As the dispersion is tested at each station to determine if an observation is consistent with a lightningproduced sferic (e.g., Rodger et al., 2005), such sferics may be rejected. This rejection may explain the lower detection ability at short ranges from the WWLLN station. The plots show that during nighttime, the detection ability falls off more slowly with distance, becoming zero around 14$15 \mathrm{Mm}$ distance. The Darwin detection range findings are representative of all the WWLLN stations. Note that the ratio does not reach one, particularly during local midnight conditions. We interpret this finding as due to lightning detected by the necessary 5 stations, without Darwin participating in the detection. Due to higher attenuation in the daytime ionosphere, it is less likely for a sferic to trigger 5 stations excluding Darwin around noon than around midnight, making the maximum noon ratio larger than the maximum midnight ratio. Note that if we only include lightning reported by exactly 5 stations including Darwin, the ratio would always be 1 , such that values which lie below 1 are caused by multiplestation detection of lightning.

\section{Estimate of WWLLN global detection efficiency}

As noted by Rodger et al. (2005), a rough estimate the WWLLN regional detection efficiency can be made by ex- amining the mean lightning rate reported by the network. Optical Transient Detector observations indicate that the expected mean geographic global annual average flash rate is $44 \pm 5$ flashes per second (Christian et al., 2003). In contrast, the mean "high quality" WWLLN lightning rate in 2004 was 0.63 per second, indicating that the WWLLN detected very roughly $\sim 1.5 \%$ of the global total lightning. Following the argument in Rodger et al. (2005) concerning the distribution of detected IC and CG discharges, this suggests that in 2004 WWLLN reported good locations for $\sim 2.3 \%$ of global CG activity. Comparisons between the regional maxima in the Carnegie curves and WWLLN data (e.g., Rodger et al., 2005) allow rough estimates of the regional variation in WWLLN DE. This study reported that there was a strong regional variation in the WWLLN DE, showing that the DE in the case of the Maritime Continent was $\sim 3$ times larger that that of the Americas. While we can compare lightning rates reported by the WWLLN and commercial networks, regional observations cannot be applied across the network in a deeply meaningful fashion, beyond the first order estimates described above. The receiving stations which make up the WWLLN do not have identical receiving hardware, local noise levels or absolute triggering levels, although they do use identical software algorithms. Thus, in order to investigate this in more detail we have developed a first principles detection efficiency model to describe the WWLLN, combining calibration information for each station with theoretical modelling to describe the expected amplitudes of the VLF sferics observed by the network. The detailed development of this model is describing in the following sections.

\subsection{Observation of known transmitters in WWLLN Spectra}

Each WWLLN receiver records the local VLF waveform using a standard 16-bit computer soundcard. Thus the uncalibrated observations at each WWLLN station are initially in sound card units. In addition to the routine sferic processing, each station records a 15 -s broadband VLF waveform every 10 minutes, containing $\sim 0-24 \mathrm{kHz}$ VLF observations. The waveform is used to produce an image of the local spectra, which is viewable from the WWLLN primary website: http://webflash.ess.washington.edu/. Calibration of a given WWLLN station is possible using the waveform files through the presence of known signals in the waveform, allowing the local sound card units to be calibrated into absolute electric field values. The known signals in the waveforms are produced by very powerful man-made transmitters that operate from established receiver locations at fixed frequencies (e.g, Byron, 1996; Barr et al., 2000). As the transmitters often serve strategic military forces they require near-continuous operation. The 15-s power spectral density derived from the waveform file from the WWLLN station in Dunedin, New Zealand, at 02:00 UT on 3 December 2004 (i.e., within $2 \mathrm{~h}$ of local noon) is shown in Fig. 8 in dB relative to an arbitrary value. Several VLF transmitters are present above $\sim 11 \mathrm{kHz}$. 
The first three thin spikes are due to the un-modulated signals from the Russian "Alpha" navigation network operating at $\sim 11.9,12.6$, and $14.9 \mathrm{kHz}$. A number of powerful VLF communications transmitters are seen at higher frequencies, the strongest of which is the US Navy transmitter located at the North West Cape of Australia, operating at $19.8 \mathrm{kHz}$. This transmitter is $\sim 6 \mathrm{Mm}$ from Dunedin, which is comparatively local for VLF propagation.

The received amplitudes of known VLF transmitters are extracted from the waveform files in sound card units, corrected for the frequency-varying WWLLN receiver amplitude response (Dowden et al., 2002). This extraction was tested by comparing the $10 \mathrm{~min}$ resolution uncalibrated amplitudes received in Dunedin from known VLF transmitters with those reported by the $0.2 \mathrm{~s}$ resolution narrowband AbsPAL receiver (e.g., Thomson et al., 2005). During the WWLLN "Calibration Campaign" period (14-17 April 2005) waveform files were downloaded every $10 \mathrm{~min}$ from each station. However, due to the large amounts of traffic involved ( $\sim 3 \mathrm{Mb}$ per file), and the internet charging regime imposed on New Zealand universities, downloads were limited to periods for which the transmitter-receiver paths were daylit. The daytime ionospheric D-region, which defines the boundary of the Earth-ionosphere waveguide in which the VLF sferics propagate, is dominated by the energy inputs from the Sun (e.g., Hargreaves, 1992). For this reason the daytime D-region has proved easier to characterise (McRae and Thomson, 2000) than the nighttime case, allowing for accurate modelling of VLF subionospheric propagation.

\subsection{Contrast with theoretical values}

The expected absolute amplitude received for each known VLF transmitter at each WWLLN receiver is predicted using a VLF subionospheric propagation model, termed LWPC. The NOSC Long Wave Propagation Capability (LWPC) code (Ferguson and Snyder, 1990) is inhomogeneous on a global scale and utilizes global ionospheric and ground conductivity maps. The code computes modal conversion along the propagation path on a continual basis and is widely regarded as the most realistic model for VLF propagation. We allow all parameters to vary in the usual manner using the standard LWPC ionosphere, with the exception that the daytime ionospheric D-region electron density profiles along the path is dependent on solar zenith angle following McRae and Thomson (2000). We find that there is a constant scaling factor between the WWLLN observed amplitudes and those calculated by LWPC. By contrasting the WWLLN-determined received VLF transmitted amplitudes in local sound card unit measurements with those predicted by the LWPC code for transmitters with known location and radiated power, and the variation of both across the day, the sound card unit transformation for each station into $\mathrm{V} / \mathrm{m}$ has been determined.

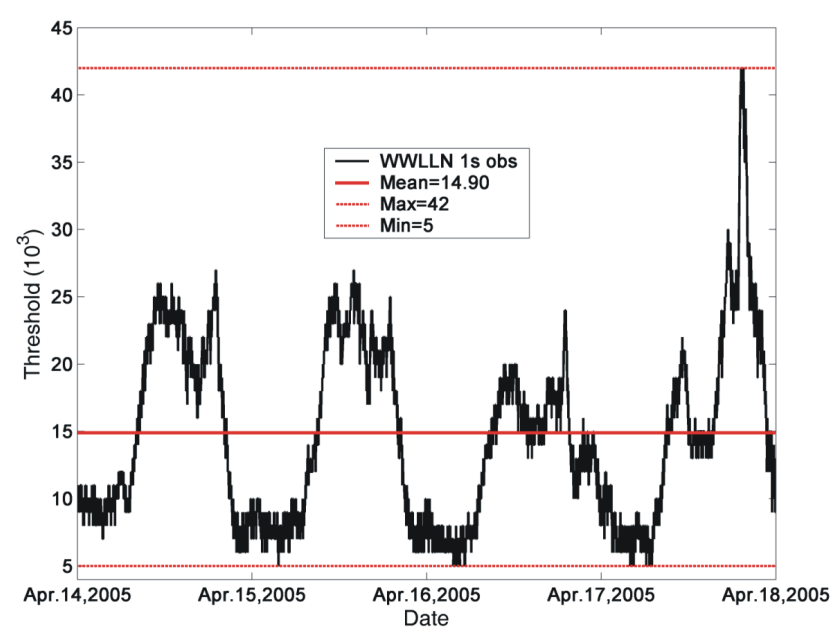

Fig. 9. Variation in the triggering threshold (in sound card units) at the Dunedin, New Zealand, WWLLN station during the 2005 calibration campaign. The horizontal lines indicate the maximum, mean, and minimum threshold values.

\subsection{Determination of trigger threshold}

WWLLN stations do not trigger at an absolute electric field value, but rather when the change in the received VLF waveform between two soundcard samples surpasses a given threshold. In addition, the triggering threshold varies over time at each station to limit the maximum number of triggers a station may return to the central processing computer (CPC) each second (Rodger et al., 2004). This automatic threshold control approach stops a receiving station from triggering at an unrealistically high rate and flooding the CPC with bad TOGA values. The varying threshold value must also be incorporated into the WWLLN detection efficiency model. During the mid-April 2005 calibration campaign, the 1-s varying threshold (in sound card units) was logged for each WWLLN station. An example of this variation is given in Fig. 9, showing the threshold level at the Dunedin WWLLN station. Triggering occurs when the difference between successive samples exceeds the threshold, $V_{t h}$ (shown in Fig. 9) which is effectively a value of the difference sound card units between two successive samples $20.8 \mu \mathrm{s}$ apart. The horizontal lines in the figure indicate the maximum, mean, and minimum threshold values (top to bottom). Generally, the threshold varies in a well-behaved manner based on the local VLF broadband noise levels. In the late morning of 18 April 2005 NZST (shown in the figure as the Universal Time evening of 17 April 2005) the threshold rapidly increases, probably due to thunderstorm activity in the New Zealand region.

In order to describe the typical state of the WWLLN in our detection efficiency model we make use of the mean threshold value. The variation seen in Fig. 9 shows that the threshold can, however, vary significantly. Indeed, the automatic 


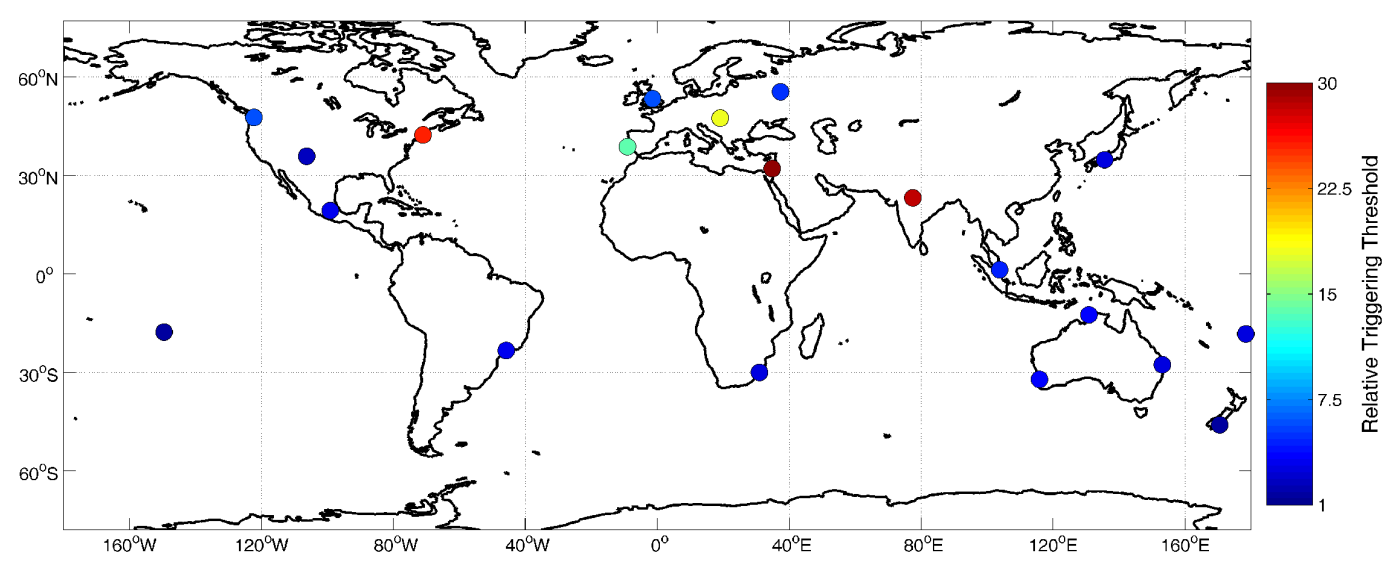

Fig. 10. Sensitivity of the WWLLN stations during the April 2005 calibration campaign, shown relative to the station which triggered for the smallest change in received absolute waveform.

threshold control approach makes it difficult to develop a description of the WWLLN detection efficiency which is representative for a significant time period. In addition, at this time normal network operation does not include sending the triggering threshold back to the CPC for archiving. This varying parameter should be recorded for future analysis.

\subsection{Global E-field changes required to trigger the WWLLN network}

WWLLN stations trigger, capturing a sferic waveform, when the change between two samples of the received VLF-band waveform exceeds a given value (Dowden et al., 2002; Rodger et al., 2004). Having established the mean triggering thresholds for each station (in sound card units), and the scale-factor by which the waveform amplitudes in sound card units are converted to absolute electric field values, the threshold triggering value in $\mathrm{V} / \mathrm{m}$ between two successive samples $20.8 \mu$ s apart (i.e., sampled at $48 \mathrm{kHz}$ ) has been determined for each station. The global variation in mean threshold triggering value is shown graphically in Fig. 10, given relative to the most "sensitive" WWLLN station, i.e. that which triggers for the smallest change in received absolute waveform (Tahiti). Note that during the calibration campaign period there was a $\sim 25-30$ ratio in station sensitivity across the network, where the most sensitive station triggered on a $\sim 14 \mathrm{mV} / \mathrm{m}$ change in the received waveform between two samples.

\section{Prediction of detection efficiencies during calibration campaign}

\subsection{VLF sferics from a "typical" CG discharge}

In order to determine if a WWLLN station will trigger for a given VLF sferic, the received waveform from a "typical" CG lightning discharge is calculated using LWPC, following the approach outlined by Cummer (1997). To determine the VLF radiated fields we first model the net current-moment of the return stroke channel, which is given by (Jones, 1970)

$i(t) \cdot l(t)=i_{g 0} v_{0} / \gamma[\exp (-a t)-\exp (-b t][1-\exp (\gamma t)]$,

where $i_{g 0}=20 \mathrm{kA}, a=2 \times 10^{4} \mathrm{~s}^{-1}, v_{0}=8 \times 10^{7} \mathrm{~ms}^{-1}, \gamma=$ $3 \times 10^{4} \mathrm{~s}^{-1}$, and $b=2 \times 10^{5} \mathrm{~s}^{-1}$. Equation (1) leads to a cloud to ground return stroke peak current of $13.9 \mathrm{kA}$ (c.f. a median return stroke peak current of $28 \mathrm{kA}$ (Popolansky, 1972)), and so the CG current is scaled by 2 to described a typical discharge. The Cummer (1997) study describes how to use LWPC-like VLF propagation models to calculate realistic received waveforms radiated by a CG discharge, including the frequency-dependent antenna response. Cummer and co-authors have made use of this approach to probe the ionospheric D-region with lightning-generated VLF sferics at NLDN-determined locations, by changing the ionospheric electron density profiles to obtain the "best fit" to the received waveforms (e.g., Cummer et al., 1998).

In our case we are not concerned with probing the ionospheric D-region, but rather describing the sferic waveforms which will be observed by the WWLLN receivers. Thus in our case we use the standard LWPC suggested ionospheric electron density profiles, albeit with the modification of Mcrae and Thomson (2000). The LWPC calculation allows us to determine the VLF waveform $(0-24 \mathrm{kHz})$ received at any WWLLN station due to a CG lightning discharge occurring at a given location. This calculation is undertaken for a grid of discharge locations to every WWLLN station, describing the sferics received from each grid location by the entire network. As the calculation of each waveform at each station is computationally intensive, a $10^{\circ}$ latitude and longitude resolution is used for the spatial grid, limited to lightning located between $60^{\circ} \mathrm{N}-60^{\circ} \mathrm{S}$, as little lightning occurs outside these latitudes (e.g., Fig. 2). 


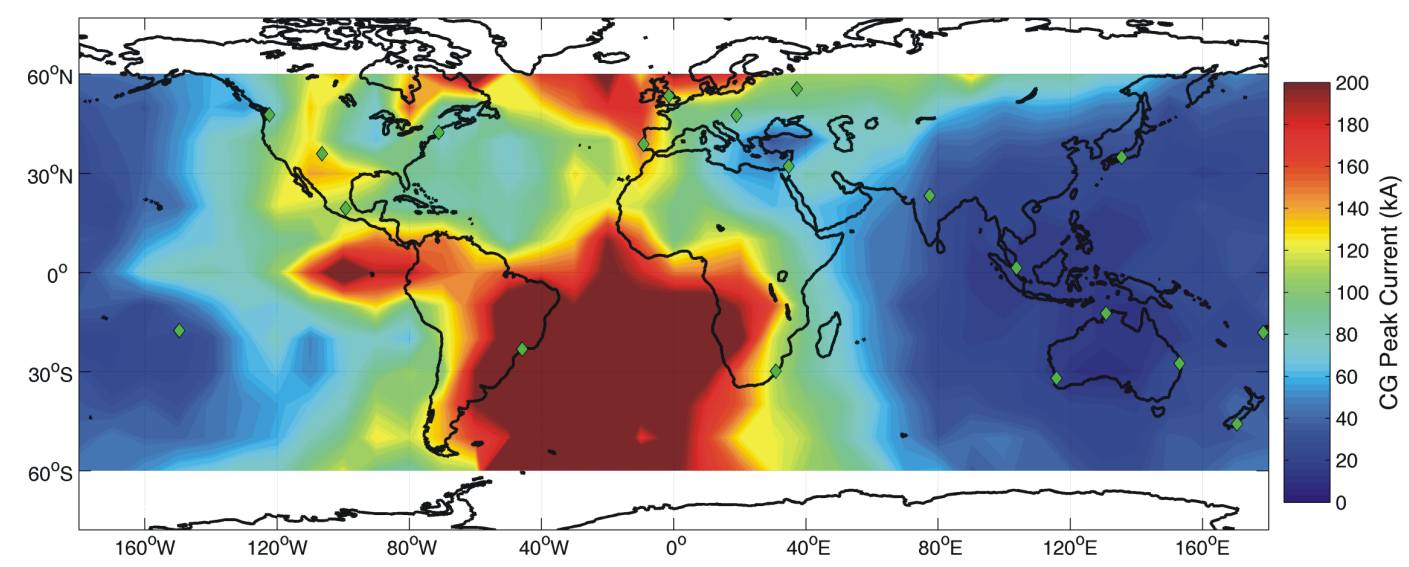

Fig. 11. Globally varying minimum CG return stroke peak current required for WWLLN detection. Modelling undertaken with the ionospheric conditions expected for 12:00 UT on 16 April 2005.

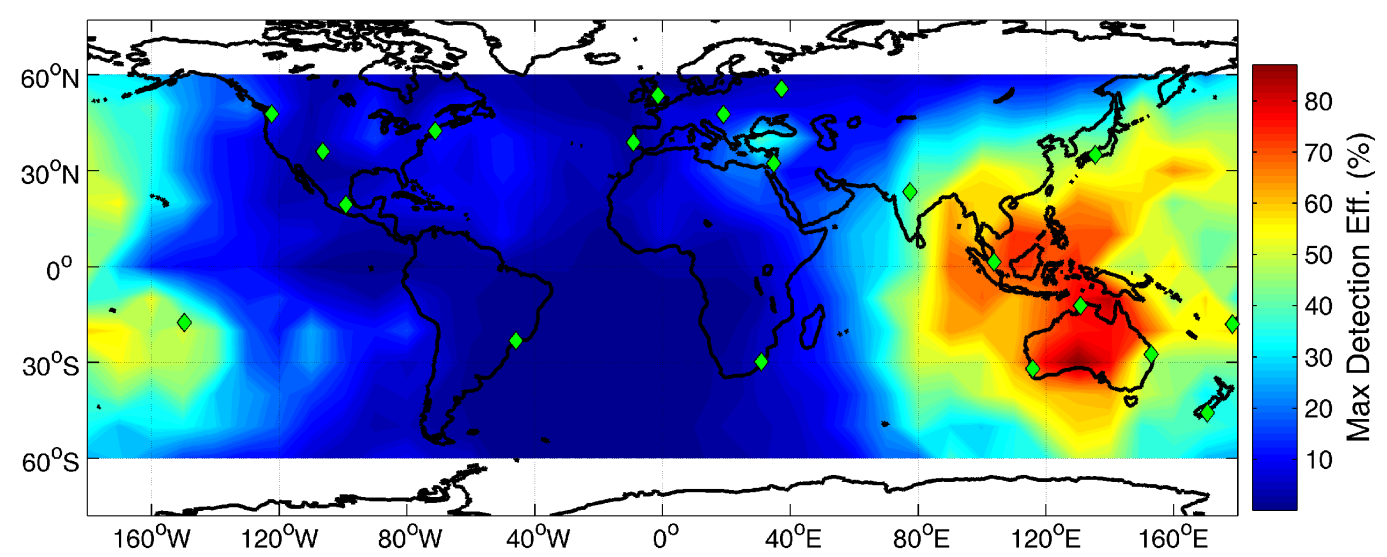

Fig. 12. Globally varying maximum WWLLN CG detection efficiency, on the basis of the mean triggering thresholds determined in Sect. 5.3 and assuming a "perfect" combination algorithm. Modelling undertaken with the ionospheric conditions expected for 12:00 UT on 16 April 2005 .

\subsection{WWLLN detection of VLF sferics and DE}

Observations from at least 5 WWLLN stations are needed to produce a "good" observation. Only 4 stations are needed to provide a distinct location, but five provides better elimination of multi-packet sets, and hence "good" locations. Having determined the typical VLF waveform $(0-24 \mathrm{kHz})$ received at the WWLLN stations due to a lightning discharge at a given location, this information can be used to find the 5 stations where the largest changes in the waveform will be observed. These 5 stations represent the minimum WWLLN detection required to produce a high quality location. On the basis of the electric field change thresholds required for all 5 of those stations to trigger, a minimum return stroke peak current is determined such that a lightning in the given location could be detected by the WWLLN. The cumulative probability distribution of return stroke peak currents in cloud to ground discharges is known (Popolansky, 1972), and thus the potential DE of the network is provided by the percentage of total lightning which are equal to, or greater than, the minimum return stroke peak current. Note that this approach assumes that the algorithm used to combine TOGA values into lightning locations is perfect, i.e., that the only factors determining the WWLLN DE are concerned with station triggering. As will be seen below, the TOGA combination algorithm is imperfect in practice. Thus the calculation described above provides the potential maximum detection efficiency of the network.

Figure 11 shows the globally varying minimum detectable CG return stroke current for the WWLLN during the calibration campaign. In this case LWPC propagation modelling was undertaken for the global ionospheric conditions expected at 12:00 UT on 16 April 2005. Clearly, the low station density in South America and southern Africa during the campaign period means only very high-peak current CGs were detectable from these regions, leading to a global mean 


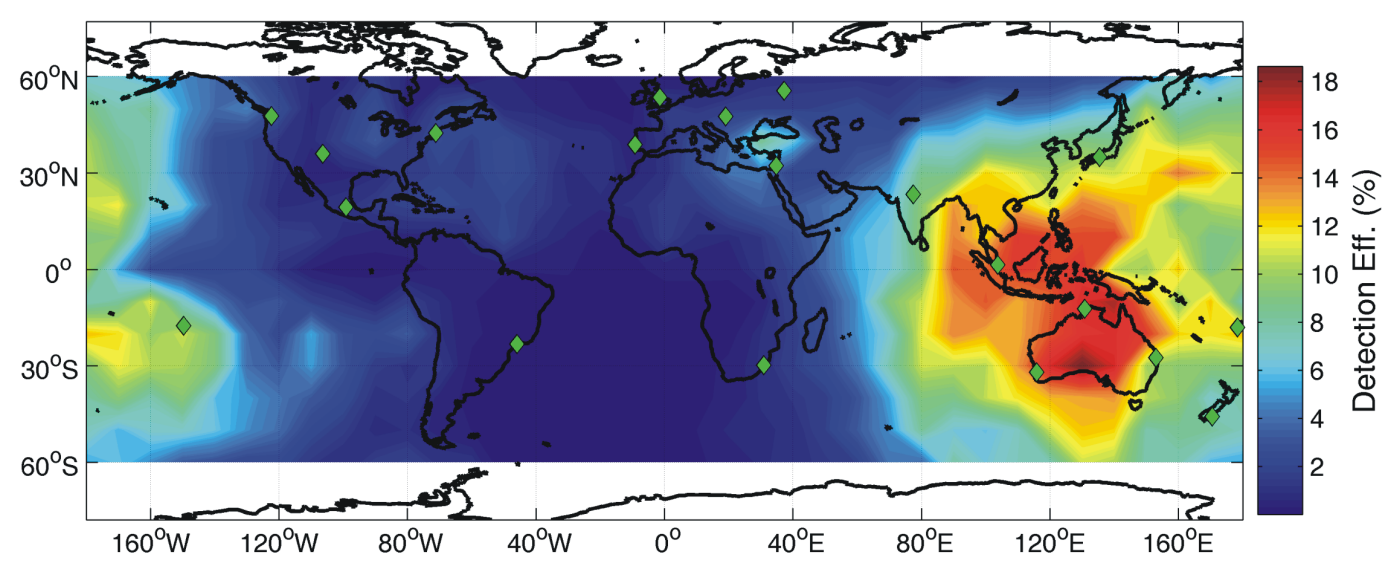

Fig. 13. Globally varying estimated WWLLN CG detection efficiency, based on the modelling and comparison with the NZLDN commercial network. Modelling undertaken with the ionospheric conditions expected for 12:00 UT on 16 April 2005.

minimum detectable peak current of $\sim 90 \mathrm{kA}(\sim 8 \%$ of CGs, Popolansky, 1972). This global mean contrasts with that for the New Zealand region, where the minimum detectable CG peak current is $\sim 37 \mathrm{kA}$ ( $37 \%$ of CGs).

Figure 12 presents the globally varying theoretical maximum WWLLN detection efficiency during the calibration campaign period (mid-April 2005), on the basis of the mean triggering thresholds determined in Sect. 5.3 and the minimum detectable currents in Fig. 11. With the assumption of a perfect combination algorithm WWLLN had a globally averaged maximum detection efficiency of $23 \%$, ranging from $\sim 50 \%$ in the longitude sectors of the Maritime Continent $\left(80^{\circ}-180^{\circ} \mathrm{E}\right)$ to $7 \%$ in the longitude sectors of the Americas $\left(130^{\circ}-40^{\circ} \mathrm{W}\right)$. Note that the detection efficiency in the Americas is lower than one would expect simply from the station density. This is largely due to the low sensitivity of the WWLLN station on the US East Coast. The relative sensitivity of WWLLN stations will strongly affect the regional detection efficiency, and as such requires further examination by the network operators. Our modelling shows that with a "perfect" TOGA combination algorithm, the April 2005 WWLLN could not meet its suggested goal of a $50 \%$ detection efficiency. Nonetheless, even the configuration from April 2005 had the potential to provide good coverage for much of the globe, particularly the Maritime Continent.

\subsection{Modelled DE based on regional comparisons}

However, the modelling presented above predicts that the detection efficiency for the New Zealand region should be $\sim 37 \%$, considerably larger than we established in Sect. 3.2, and reflects the inefficiencies in the existing algorithm used for combining the TOGA measurements so as to produce a lightning location. WWLLN detected $\sim 8 \%$ of NZLDN CGs with currents of $35 \mathrm{kA}$ (Fig. 5), roughly the minimum detectable CG peak current in this region, allowing us to estimate the efficiency including the limits imposed by this al- gorithm. Figure 13 shows the WWLLN DE taking this into account. Note that this leads to very different detection efficiencies between New Zealand and Australia. The calculated DE for South-Eastern Australia is only about half that reported for a single day's lightning observations in January 2004 (Rodger et al., 2005). This apparent decrease probably reflects the variable nature of the network and the decreasing efficiency of the existing TOGA combination algorithm with increasing global station number. Rodger et al. (2004) reported on the algorithm by which each TOGA measurement from the WWLLN stations are combined to select a common stroke. This process is still used, modified with additional tests on the observed sferic (Rodger et al., 2005). However, with the growing global network it is more and more likely that a set of TOGA for a stroke may be "contaminated" by near-simultaneous observations occurring elsewhere in the network of sferics from a different discharge. The decreasing efficiency of the existing TOGA combination algorithm is a recognised problem inside the WWLLN consortium, and is further discussed in Sect. 8.1.

\subsection{Variation in DE due to VLF propagation}

As WWLLN relies upon propagation of the VLF sferic beneath the ionosphere, WWLLN detection efficiencies will depend on the changing nature of the ionospheric D-region. In order to determine the significance, we have repeated our LWPC calculations for the global ionospheric conditions expected at 00:00 UT on 16 April and 12:00 UT on 16 October. Figure 14 presents the WWLLN DE for 00:00 UT on 16 April. This figure should represent the largest differences due to changing VLF propagation, and is to be contrasted with Fig. 13. There are significant increases in the estimated DE in the Maritime Continent, as VLF propagates with less attenuation beneath the nighttime D-region. The effect is considerably less significant in Europe and the Americas, indicating that the dominant effect in setting the DE 


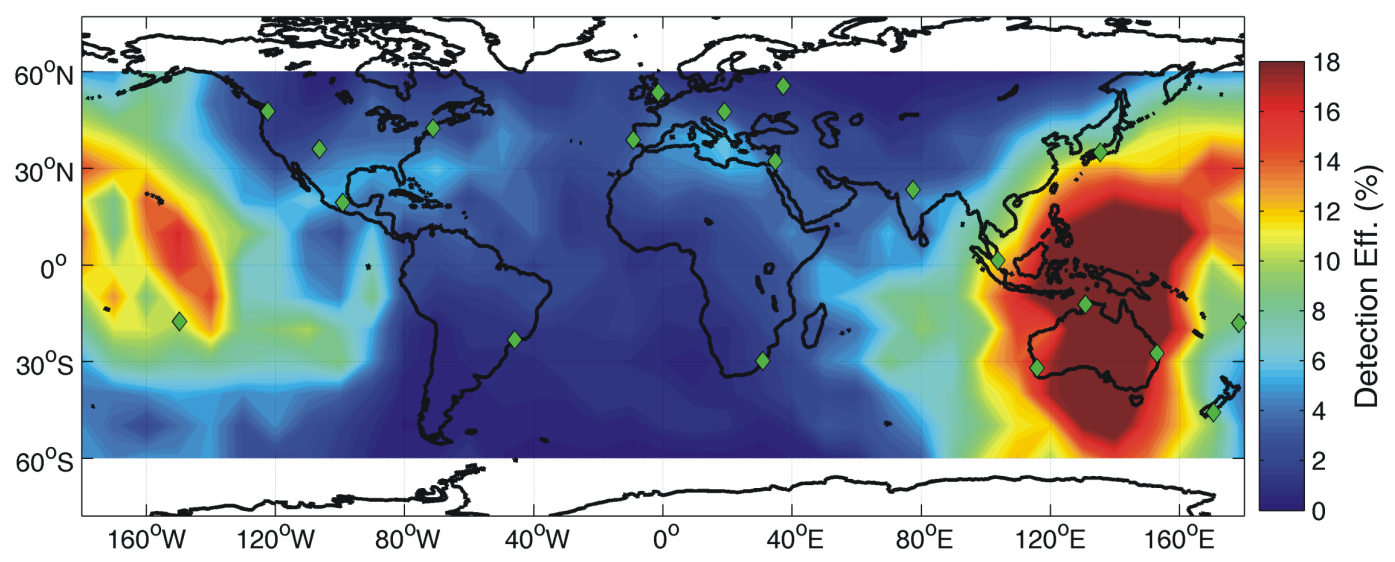

Fig. 14. Globally varying estimated WWLLN CG detection efficiency, for comparison with Fig. 13. Modelling undertaken with the ionospheric conditions expected for 00:00 UT on 16 April 2005.

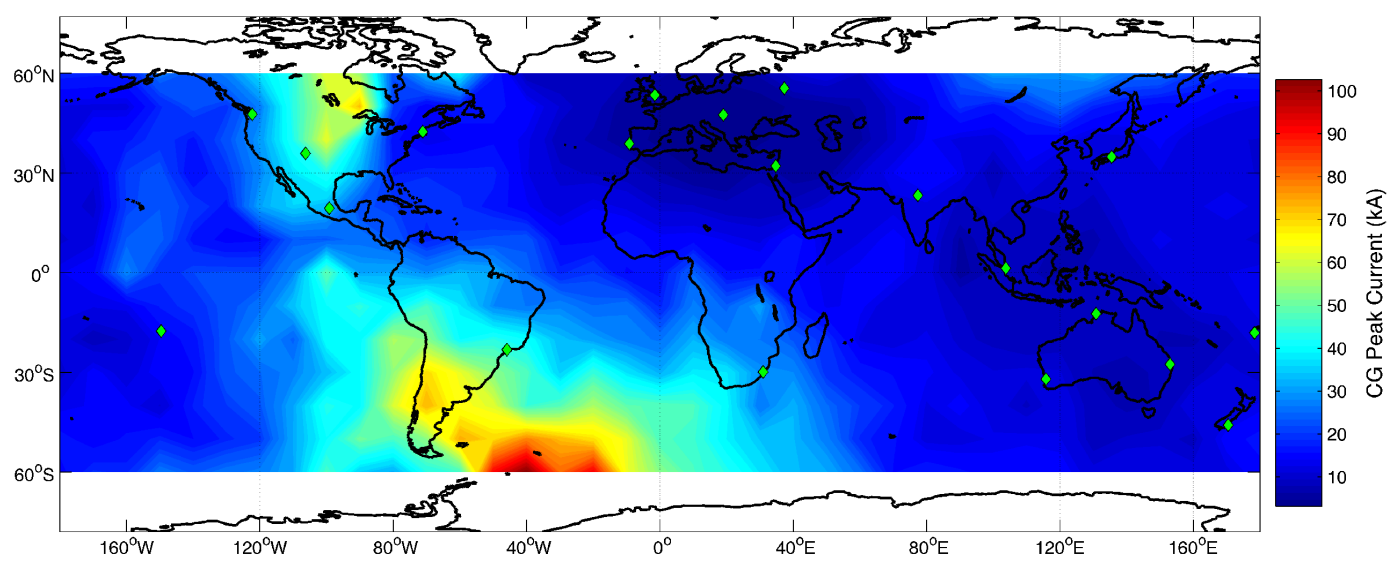

Fig. 15. Globally varying minimum CG return stroke peak current required for WWLLN detection assuming all WWLLN stations had the same sensitivity as Tahiti. To be contrasted with Fig. 11.

of WWLLN in these regions are the station locations and thresholding. In the Australian region there is a $\sim 3-5 \%$ increase in DE, while the largest improvements of $\sim 10 \%$ occurs for locations near Papua New Guinea. The large change near Papua New Guinea corresponds to DE changing by $\sim 25 \%$, indicating the significance of diurnal cycles in VLF propagation to the WWLLN DE. However, in contrast, the differences between April and October are very slight (not shown), with no DE differences larger than $\sim 1 \%$.

\section{Estimate of potential DE of campaign-period WWLLN network}

In the analysis above we argued that the thresholding and sensitivity of the WWLLN stations were highly important factors in the global variation in WWLLN DE. Figure 15 shows the globally varying minimum detectable CG return stroke current for the WWLLN assuming all stations had the sensitivity of Taihiti. This forced "recalibration" of the network leads to major reductions in the minimum current required to trigger the network, and therefore would produce major changes in the DE of the network. In this case the global mean return stroke current required to trigger the network decreases to $22 \mathrm{kA}$. Such high sensitivities would make the WWLLN much more likely to meet its DE target. However, it should be noted that this would lead to a large increase in data traffic inside the network, which could create difficulties for some station hosts. While the planned improvements in the TOGA combination algorithm will make more efficient use of the data, improving the varying sensitivity of the WWLLN stations would also improve the DE.

\section{Estimate of DE of current WWLLN network}

Significant changes have been made to the network since the April 2005 calibration campaign, primarily in the form of 

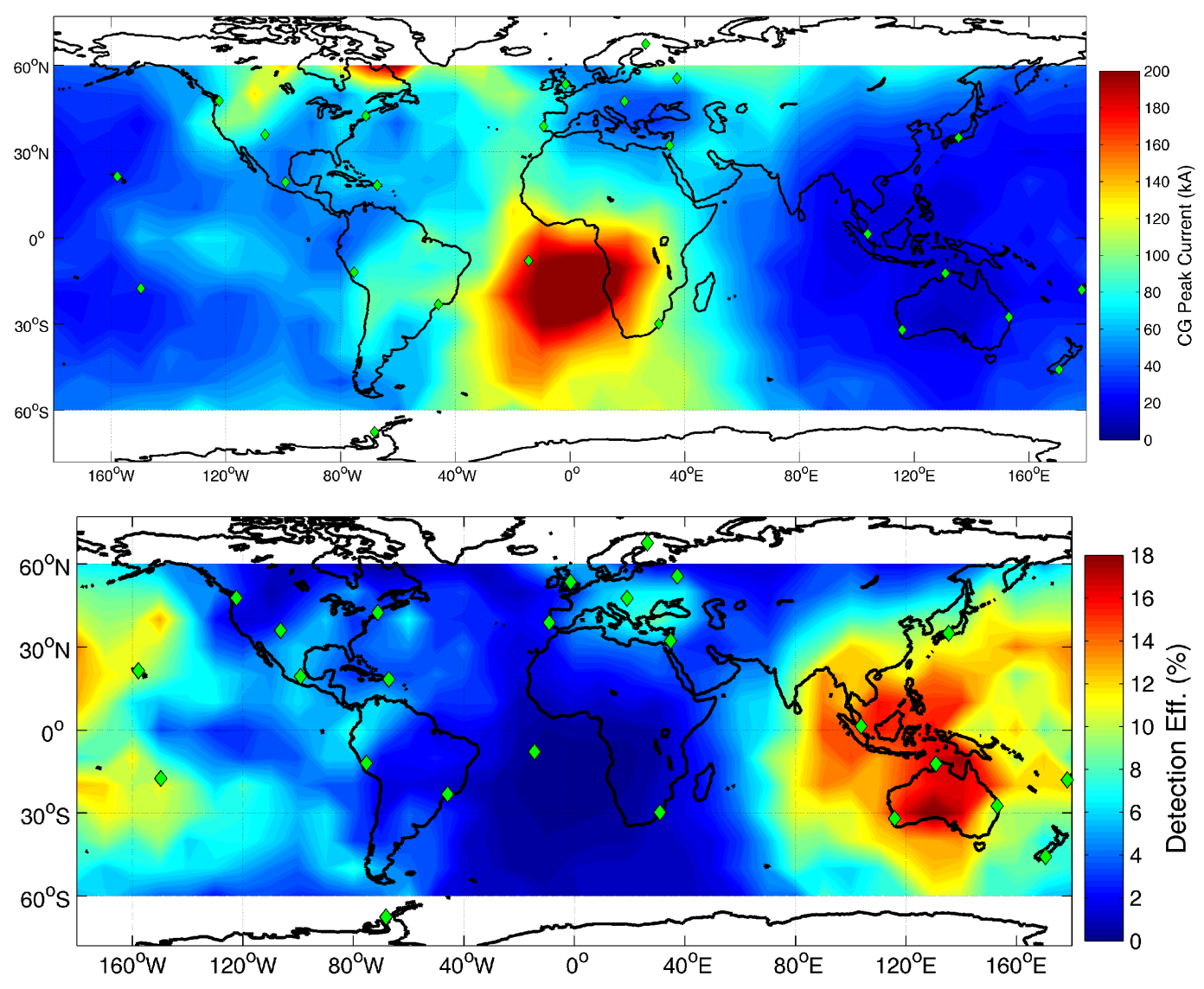

Fig. 16. Estimates of the minimum CG return stroke peak current (top panel) and detection efficiency (lower panel) for the April 2006 WWLLN.

additional WWLLN stations in the longitudes of the Americas. Making use of our first-principles model described above, we can estimate the DE of the April 2006 WWLLN as shown in Fig. 16. Here we have assumed that the sensitivity of the stations is unchanged from the April 2005 calibration period, and undertaken our modelling for the ionospheric conditions expected at 12:00 UT on 16 April 2005. The 6 new WWLLN stations (shown as yellow diamonds in Fig. 1) are assumed to have "average" sensitivities based on the calibration period (Fig. 10). Both of these are significant assumptions that will need to be tested during the automated calibration process outlined below. The upper panel of Fig. 16 shows the minimum CG return stroke peak current required to trigger 5-WWLLN stations, while the lower panel shows the estimated DE of the existing network. These panels should be contrasted with Figs. 11 and 13, respectively. As expected, the addition of the extra WWLLN stations leads to decreased peak currents required for triggering in the American sector, as well as improved DE. The additional station in northern Europe also leads to a major improvement in DE in the Mediterranean region. The most significant improvement in terms of coverage, however, is in eastern South America and the South Atlantic, where the sta- tions at Rothera and Ascension Island together bring much lower minimum triggering currents.

\section{Discussion}

\subsection{Future improvements}

A number of improvements are currently planned for the WWLLN. As shown in Fig. 1, new stations are planned, and the coverage of the network is growing steadily. With increasing WWLLN coverage, the existing algorithm has proved less flexible than was hoped. A new TOGA grouping algorithm is currently under development which produces more high-quality lightning locations than the existing approach. In particular, the new algorithm is less sensitive to interference from the observation of multiple different lightning events across the network in the same time period. The DE of the network will need to be re-examined at this point, as additional stations plus the improved algorithm are expected to lead to large improvements in detection efficiency.

The WWLLN consortium now plans to introduce automatic calibration of the network, making use of the approach 


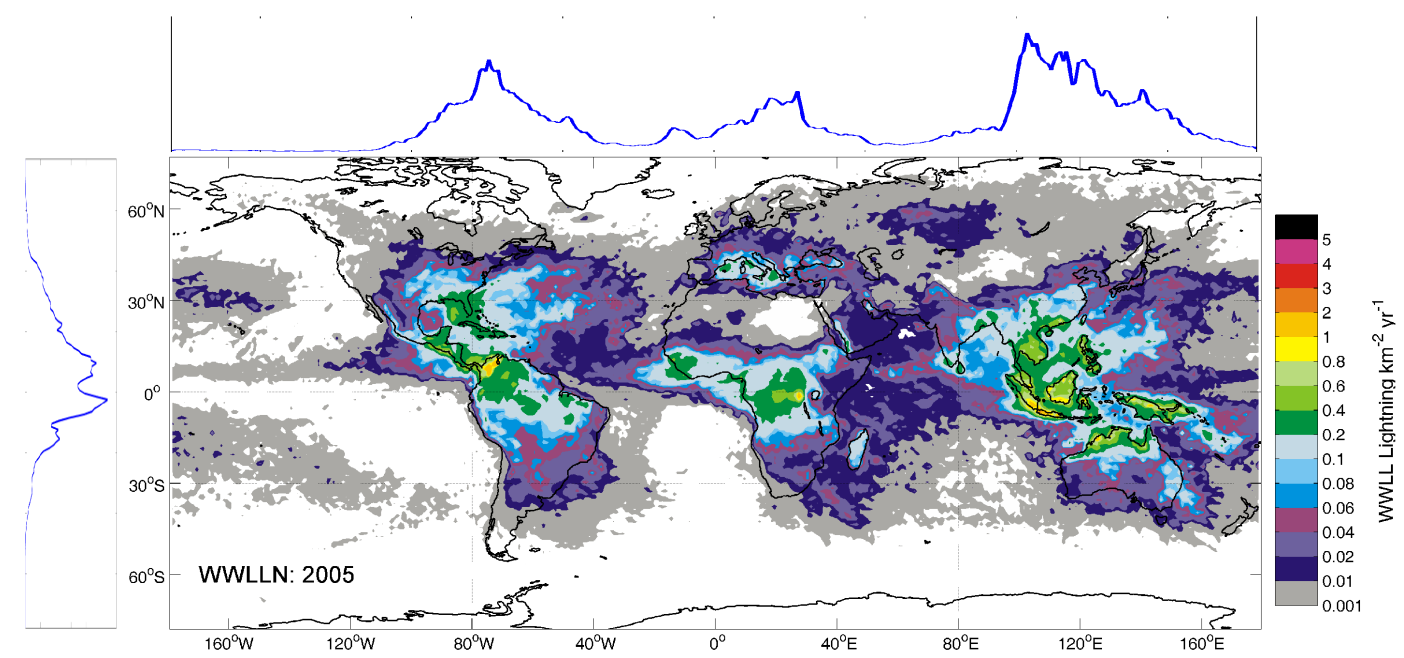

Fig. 17. Summary of 2005 WWLLN lightning activity, in the same format as Fig. 2.

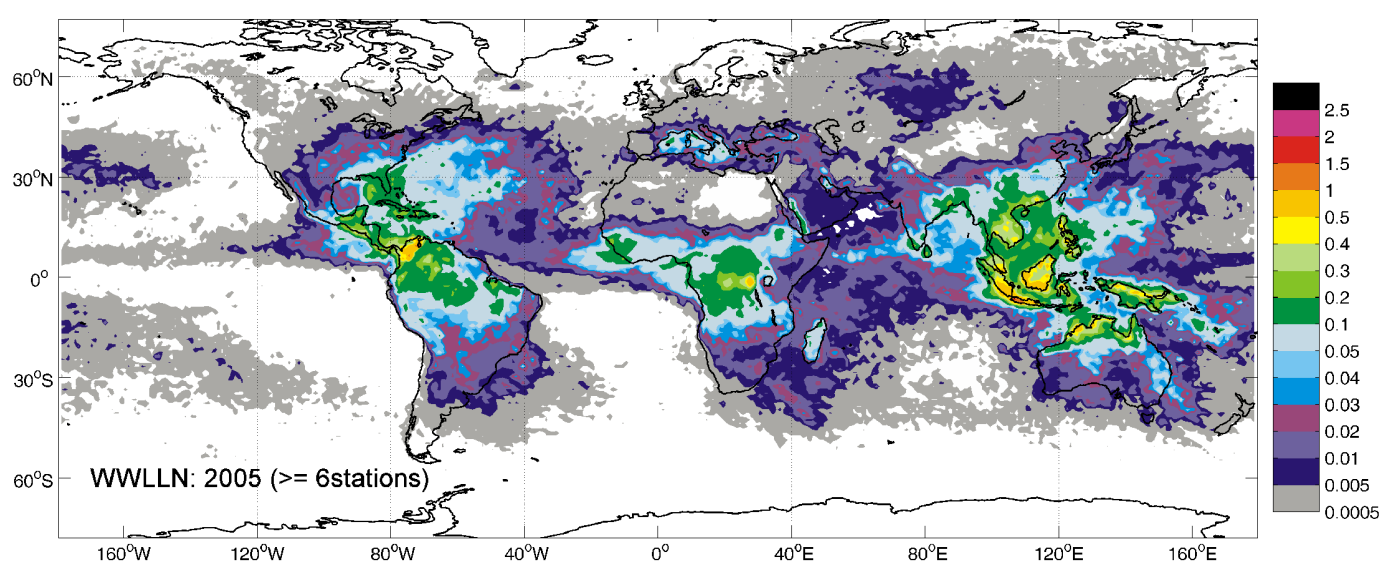

Fig. 18. Summary of 2005 WWLLN lightning activity, in the same format as Fig. 17, but including only the 10.1 million locations observed by 6 or more stations. Note the contour thresholds have been divided by 2 .

outlined in this paper. Automatic calibration will allow regular monitoring of the detection efficiency of the network. In addition, calibration will also allow WWLLN to measure the radiated power of each detected lightning discharge, and hence provide an indication of the strength of global lightning in real time.

\subsection{5 global statistics}

Figure 2 presented the global lightning activity reported by the WWLLN for 2004. With increasing station density, the global coverage of the network is steadily improving. This enhancement is emphasized by Fig. 17, which shows the WWLLN 2005 global lightning activity in the same format as Fig. 2. This plot includes all 18.1 million "high quality" WWLLN locations from this year. Note that the upper and left hand panels presenting the longitudinal and latitudinal variation in WWLLN-detected lightning indicates significant improvement in WWLLN coverage in the Americas. The additional stations deployed in this sector will continue this improvement expected in the 2006 data (e.g., Peru and the Antarctic Peninsula).

Figure 18 shows the WWLLN 2005 global lightning activity, including only the 10.1 million locations which were observed by 6 or more stations (c.f. 5 of more stations in Fig. 17). Here the contour thresholds have been divided by 2 to compensate for the decrease in the number of events. The pattern of lightning activity is essentially the same between the two figures, suggesting that the primary difference between the two datasets is an alteration in the minimum peak current threshold required to trigger the necessary stations. Thus while the detection efficiency of the WWLLN is low, it is not clear that the distribution of global lightning activity will be significantly different as the network DE is improved (e.g., by a factor of 2), and additional lower current 
lightning is included. This is fundamentally consistent with the regional study of Jacobson et al. (2006), who concluded that WWLLN supplies a "spatially accurate and representative census of storms".

\subsection{The significance of high-peak current lightning}

Barrington-Leigh and Inan (1999) reported that all NLDNdetected CGs with return stroke peak currents greater than $55 \mathrm{kA}$ produced elves, while $\sim 70 \%$ of CGs with currents $>45 \mathrm{kA}$ produced elves. If one assumes that the elveproducing threshold is $\sim 50 \mathrm{kA}$, this suggests that $25 \%$ of CG discharges (Popolansky, 1972) will produce elves. Given that the mean global flash rate is 44 per second (Christian et al., 2003), and there are $~ 3.5$ times more IC lightning flashes than CG flashes (albeit with a factor of 2 uncertainty) (Mackerras et al., 1998), this suggests that the global mean elve rate should be as high as $\sim 3.5$ per second, or 210 elves per minute. This elve rate is significantly larger than the estimated global mean sprite rate of $\sim 3$ per minute (Fullekrug, 2005), reasonably consistent with the ISUAL satellite observations of elves and sprites which showed vastly more elves than sprites (Mende et al., 2005). In addition, if we conservatively assume that each elve affects an atmospheric region $100 \mathrm{~km}$ in radius, while sprites affect a region $\sim 20 \mathrm{~km}$ in radius, it is clear that elves impact a vastly larger region of the upper atmosphere than sprites $(\sim 1750$ times larger), interacting with the upper atmosphere across a surface area $>1 \%$ of that of the Earth each minute. Clearly, the energy inputs from lightning EMP that lead to elves have the potential to significantly influence the ionosphere on regional scales, as suggested by some studies (e.g., Rodger et al., 2001).

The WWLLN is well suited to the study of lightningEMP and its impacts upon the upper atmosphere. The minimum peak current calculations described above indicate that $\sim 75 \%$ of all WWLLN-reported lightning will have peak currents $>50 \mathrm{kA}$. Thus the 2005 WWLLN observations will provide lightning locations for $\sim 12 \%$ of the global elve activity, based on the observed WWLLN elve-producing lightning rate of 26 flashes/min $(75 \%$ of $\left.18.1 \times 10^{6} /(365 \times 24 \times 60)\right)$.

\section{Summary}

An experimental VLF World-Wide Lightning Location Network (WWLLN) has been developed through collaborations with research institutions across the world. The aim of the WWLLN is to provide global real-time locations of lightning discharges, with $>50 \%$ CG flash detection efficiency and mean location accuracy of $<10 \mathrm{~km}$. In the last $\sim 5$ years the network has expanded from a limited number of stations in the Western Pacific to its April 2006 state of 25 stations which cover much of the globe, with additional stations planned in the near future. Several previous studies have considered the detection efficiency of the WWLLN, showing that WWLLN tends to detect high-peak current lightning discharges and that there are strong regional variations in the detection efficiency. In this paper we focused on the detection efficiency of the WWLLN, both on the regional and global scale.

An initial comparison contrasted the locations and times reported by the WWLLN with New Zealand lightning location data purchased from a commercial lightning location network. Our analysis confirmed that WWLLN favours the detection high-peak current return stroke lightning discharges, and showed that stronger lightning are observed by more stations in the global network. The NZLDN comparison showed that WWLLN has an essentially constant detection efficiency for CG lightning above a certain return stroke peak current, rapidly falling off to zero at a current threshold around $35 \mathrm{kA}$.

We went on to construct a first principles detection efficiency model to describe the detection of lightning by the WWLLN, by combining calibration information for each station with theoretical modelling. The first-principles model allowed calculation of the expected amplitudes of the VLF sferics observed by the network and thus prediction of the minimum CG return stroke peak current required to trigger the network. From the minimum currents the varying detection efficiencies were determined, showing strong spatial variations across the globe due to station density and sensitivity. VLF propagation was also shown to influence WWLLN detection efficiencies, with detection rates being about one-quarter higher in some nighttime sectors. While the WWLLN detection efficiency is both variable and significantly below the ultimate goal for the network, it is important to note that each location is highly accurate in time and space, as demonstrated by contrast with other detection networks.

WWLLN is currently best suited to study the occurrence and impacts of high peak-current lightning. For example, in 2005 about $12 \%$ of the global elve-producing lightning will have been located by the network. As the lightning-EMP which produce elves have a high mean rate (210 per minute) it has the potential to significantly influence the ionosphere on regional scales.

Acknowledgements. C. J. Rodger would also like to thank $\mathrm{N}$. Thomas of Oxford for his support. We thank the all the network hosts listed in Table 1 for housing the VLF lightning acquisition receivers, and T. Broux of the Technical University of Eindhoven for an early case study. We are grateful to the New Zealand MetService Ltd. for collecting the NZLDN data, most particularly P. Fisher and J. Glover for helping C. J. Rodger to understand its operation. This research was supported in part by the University of Washington through a grant from the Mindlin Foundation. We have profited from insightful suggestions by A. Jacobson of the University of Washington.

Topical Editor F. D'Andrea thanks two referees for their help in evaluating this paper. 


\section{References}

Barr, R., Jones, D. Ll., and Rodger, C. J.: ELF and VLF Radio Waves, J. Atmos. Sol. Terr. Phys., 62(17-18), 1689-1718, 2000.

Barrington-Leigh, C. and Inan, U. S.: Elves triggered by positive and negative lightning discharges, Geophys. Res. Lett., 26, 683686, 1999.

Byron, W. J.: The monster antennas, Communications Quarterly, 6(2), 5-24, 1996.

Christian, H. J., Blakeslee, R. J., Boccippio, D. J., Boeck, W. L., Buechler, D. E., Driscoll, K. T., Goodman, S. J., Hall, J. M., Koshak, W. J., Mach, D. M., and Stewart, M. F.: Global frequency and distribution of lightning as observed from space by the Optical Transient Detector, J. Geophys. Res., 108(D1), doi:10.1029/2002JD002347, 2003.

Collier, A. B., Hughes, A. R. W., Lichtenberger, J., and Steinbach, P.: Seasonal and diurnal variation of lightning activity over southern Africa and correlation with European whistler observations, Ann. Geophys., 24, 529-542, 2006,

http://www.ann-geophys.net/24/529/2006/.

Crombie, D. D.: Periodic fading of VLF signals received over long paths during sunrise and sunset, Journal of Research National Bureau of Standards, Radio Science, 68D, 27-34, 1964.

Cummer, S. A.: Lightning and ionospheric remote sensing using VLF/ELF radio atmospherics, Ph.D. thesis, University of Stanford, Stanford, California, 1997.

Cummer, S. A., Inan, U. S., and Bell, T. F.: Ionospheric D region remote sensing using VLF radio atmospherics, Radio Sci. 33, 1781-1792, 1998.

Cummins, K. L. and Murphy, M. J.: Overview of lightning detection in the VLF, LF, and VHF frequency ranges, 2000 International Lightning Detection Conference, Tucson, Arizona, 1-10, 2000.

Cummins, K. L., Krider, E. P., and Malone, M. D.: The U.S. National Lightning Detection Network and applications of cloudto-ground lightning data by electric power utilities, IEEE Trans. Electromagn. Comp., 40(4), 465-480, 1998a.

Cummins, K. L., Murphy, M. J., Bardo, E. A., Hiscox, W. L., Pyle, R. B., and Pifer, A. E.: A combined TOA/MDF technology upgrade of the U.S. National Lightning Detection Network, J. Geophys. Res, 103, 9035-9044, 1998b.

Dowden, R. L., Brundell, J. B., and Rodger, C. J.: VLF lightning location by time of group arrival (TOGA) at multiple sites, J. Atmos. Sol. Terr. Phys., 64, 817-830, 2002.

Ferguson, J. A. and Snyder, F. P.: Computer programs for assessment of long wavelength radio communication, Tech. Doc. 1773, Nav. Ocean Syst. Cent., San Diego, Calif., 1990.

Fullekrug, M.: Global TLE-rates and Remote Diagnostics, CAL mid-term review and science meeting, Elounda, Crete, Greece, June 20-24, abstract also available at: http://cal-crete.physics. uoc.gr/Abstracts/D5_Martin_Fullekrug_Abstract.pdf, 2005.

Fullekrug, M. and Constable, S.: Global triangulation of intense lightning discharges, Geophys. Res. Lett., 27(3), 333-336, 2000.

Hamid, E. F., Kawasaki, Z.-I., and Mardiana, R.: Impact of the 1997-98 El Nino event on lightning activity over Indonesia, Geophys. Res. Lett., 28, 147-150, 2001.

Hargreaves, J. K.: The solar-terrestrial environment: an introduction to geospace, Cambridge University Press, Cambridge, 1992.

Huang, E., Williams, E., Boldi, R., Heckman, S., Lyons, W., Taylor, M., Nelson, T., and Wong, C.: Criteria for sprites and elves based on Schumann resonance observations, J. Geophys. Res., 104(D14), 16943-16964, doi:10.1029/1999JD900139, 1999.

Jacobson, A. R., Holzworth, R., Harlin, J., Dowden, R., and Lay, E.: Performance Assessment of the World Wide Lightning Location Network (WWLLN), Using the Los Alamos Sferic Array (LASA) as Ground Truth, J. Atmos. and Oceanic Tech., A-731, 2006.

Jourdain, L. and Hauglustaine, D. A.: The global distribution of lightning NOx simulated on-line in a general circulation model, Phys. Chem. Earth Pt. C-Solar-Terr. Planet. Sci, 26, 585-591, 2001.

Jones, D. L.: Electromagnetic radiation from multiple return strokes of lightning, J. Atmos. Terr. Phys., 32, 1077-1093, 1970.

Knupp, K. R., Paech, S., and Goodman, S.: Variations in cloud-toground lightning characteristics among three adjacent tornadic supercell storms over the Tennessee valley region, Mon. Weather Rev., 131(1), 172-188, 2003.

Lay, E. H., Holzworth, R. H., Rodger, C. J., Thomas, J. N., Pinto, O., and Dowden, R. L.: WWLL Global Lightning Detection System: Regional Validation Study in Brazil, Geophys. Res. Lett., 31(3), L03102, doi:10.1029/2003GL018882, 2004.

Lyons, W. A., Nelson, T. E., Williams, E. R., Cramer, J. A., and Turner, T. R.: Enhanced positive cloud-to-ground lightning in thunderstorms ingesting smoke from fires, Science, 282, 77-80, 1998.

Mackerras, D., Darveniza, M., R. Orville, E., Williams, E. R., and Goodman, S. J.: Global lightning: Total, cloud and ground flash estimates. J. Geophys. Res., 103, 19791-19809, 1998.

Mende, S. B., Frey, H. U., Hsu, R. R., Su, H. T., Chen, A. B., Lee, L. C., Sentman, D. D., Takahashi, Y., and Fukunishi, H.: D region ionization by lightning-induced electromagnetic pulses, J. Geophys. Res., 110, A11312, doi:10.1029/2005JA011064, 2005.

Magono, C.: Thunderstorms, Elsevier Sci., Amsterdam, 1980.

McRae, W. M. and Thomson, N. R.: VLF phase and amplitude: daytime ionospheric parameters, J. of Atmos. Sol.-Terr. Phys., 62 (7), 609-618, 2000.

Orville, R. E. and Henderson, R. W.: Global distribution of midnight lightning, September 1977 to August 1978, Mon. Wea. Rev., 114, 12, 2640-2653, 1986.

Pierce, E. T.: Atmospherics and radio noise, in Lightning, vol. 1, edited by: Golde, R. H., Academic Press, New York, 309-350, 1977.

Popolansky, F.: Frequency distribution of amplitudes of lightning currents, Electra, 22, 139-47, 1972.

Rakov, V. A. and Uman, M. A.: Lightning; Physics and Effects, Cambridge University Press, Cambridge, 2003.

Rodger, C. J.: Red sprites, upward lightning, and VLF perturbations, Rev. Geophys., 37, 317-336, 1999.

Rodger, C. J., Cho, M., Clilverd, M. A., and Rycroft, M. J.: Lower ionospheric modification by lightning-EMP: Simulation of the nighttime ionosphere over the United States, Geophys. Res. Lett., 28(2), 199-202, 2001.

Rodger, C. J., Clilverd, M. A., and McCormick, R. J.: Significance of lightning generated whistlers to inner radiation belt electron lifetimes, J. Geophys. Res., 108(12), 1462, doi:10.1029/2003JA009906, 2003.

Rodger, C. J., Brundell, J. B., Dowden, R. L., and Thomson, N. R.: Location accuracy of long distance VLF lightning location network, Ann. Geophys., 22(3), 747-758, 2004. 
Rodger, C. J., Brundell, J. B., and Dowden, R. L.: Location accuracy of long distance VLF lightning location network: Post algorithm upgrade, Ann. Geophys., 23, 277-290, 2005, http://www.ann-geophys.net/23/277/2005/.

Schlegel, K., Diendorfer, G., Thern, S., and Schmidt, M.: Thunderstorms, lightning and solar activity - Middle Europe, J. Atmos. Sol.-Terr. Phys., 63, 1705-1713, 2001.

Smith, D. A., Eack, K. B., Harlin, J., Heavner, M. J., Jacobson, A. R., Massey, R. S., Shao, X. M., and Wiens, K. C.: The Los Alamos Sferic Array: A research tool for lightning investigations, Journal of Geophysical Research, 107, doi:10.1029/2001JD000502, 2002.

Thomson, N. R., Rodger, C. J., and Clilverd, M. A.: Large solar flares and their ionospheric D-region enhancements, J. Geophys. Res., 110, A06306, doi:10.1029/2005JA011008, 2005.

Uman, M. A.: The Lightning Discharge, Int. Geophys. Ser., Vol. 39, Academic Press, San Diego, Calif., 1987.
Watt, A. D.: VLF Radio Engineering, Pergamon Press, Oxford, 1967.

Whipple, F. J. W. and Scrase, F. J.: Point discharge in the electric field of the Earth, Met. Office Geophys. Mem. London, VII(68), 3-20, 1936.

Williams, E. R.: The Schumann Resonance: A global tropical thermometer, Science, 256, 1184-1187, 1992.

Yair, Y., Israelevich, P., Devir, A. D., Moalem, M., Price, C., Joseph, J. H., Levin, Z., Ziv, B., Sternlieb, A., and Teller, A.: New observations of sprites from the space shuttle, J. Geophys. Res., 109, D15201, doi:10.1029/2003JD004497, 2004.

Yair, Y., Price, C., Ziv, B., Israelevich, P., Sentman, D. D., SaoSabbas, F. T., Devir, A. D., Sato, M., Rodger, C. J., Moalem, M., Greenberg, E., and Yaron, O.: Space Shuttle observation of an unusual transient atmospheric emission, Geophys. Res. Lett., 32(2), doi:10.1029/2004GL021551, 2005. 